\title{
Study on How to Carry out Ideological and Political Education of Colleges in China
}

\author{
Hui Cheng \\ 1) Department of Foreign Language, Weifang College, Weifang, Shandong, China \\ ${ }^{2)}$ Department of Teachers' Education, Weifang College, Weifang, Shandong, China
}

\begin{abstract}
Since the Chinese Communist eighteen, ideological and political education as an important part of the socialist core values has got widespread attention and vigorously promoted in universities. However, in this process, due to a variety of factors, there are still a number of complex and controversial issues. In the long run, the effectiveness of socialist core values of Chinese higher education, depending on the proper settlement of these conflicts, but also depends on the continuing transformation and progress of the whole society.
\end{abstract}

Keywords—new Era, colleges in China, ideological and political education

\section{新时期高校思想政治教育工作浅议}

\author{
程 辉 \\ 潍坊学院外国语学院, 淮坊, 山东, 中国
}

摘 要 本中共十八大以来, 作为思想政治教育重要内容的社会主义核心价值观, 在中国高校得到普遍的重视和大力的推进。但 是, 在这个过程中, 由于多种因素的影响, 还存在着一些复杂的争议和问题。从长远看, 中国高校社会主义核心价值观教育的成效, 取决于这些矛盾的妥善解决, 同时也依赖于整个社会的持续性变革和进步。

关键词＼cjkstart新时期中国高校＼cjkstart思想政治教育

任何一个国家的高等教育, 在某种意义上, 都承担着 培养合格公民, 传播社会主流价值, 推进社会进步的重要 作用。对处于改革开放时代的社会主义中国来说, 培养合 格的社会主义建设者和接班人, 就必须在国民教育体系中 注入社会主流价值观教育的内容, 特别是在高校中进一步 加强这方面的教育。

1. 中国高校思想政治教育的新动向：社会主义核心 价值观教育

2012 年 11 月, 中共十八大报告就提出: “倡导富强、 民主、文明、和谐, 倡导自由、平等、公正、法治, 倡导 爱国、敬业、诚信、友善, 积极培育和践行社会主义核心 价值观。”2013 年 12 月, 中共中央办公厅印发《关于培育 和践行社会主义核心价值观的意见》。2014 年 2 月 12 日, 中共官方报纸《人民日报》以及各大媒体, 都明确公布了
社会主义核心价值观基本内容: “富强、民主、文明、和谐, 自由、平等、公正、法治, 爱国、敬业、诚信、友善”。社 会主义核心价值观, 是从国家层面、社会层面, 以及公民 个人层面来分别表述的。这一表述体现了在当代中国发展 语境下, 最大限度的共识, 也就是“最大公约数”。

2014 年 5 月 4 日, 中国最高领导人习近平到北京大学 考察并召开座谈会, 特别强调了核心价值观教育的问题。 他认为, 核心价值观, 承载着一个民族、一个国家的精神 追求, 体现着一个社会评判是非曲直的价值标准。他提醒 青年学生: 要努力把核心价值观的要求贯穿到日常生活中, 把它变成自觉奉行的信念理念。

对于大学生来说, 价值观的选择尤其重要。因为, 中 国党和政府历来十分重视青年工作, 把青年人特别是大学 生看作是国家的未来和希望。习近平的这段讲话, 是中国 最高领导人对中国最高学府的青年学生的重托, 体现了中 
国高层领导对高校社会主义核心价值观教育的高度重视, 同时也体现了对高校思想政治教育现状的某种忧虑和不 满。

2014 年 10 月 18 日至 19 日, 中国教育部在北京举办 直属高校党委书记校长专题研讨班。教育部党组书记、部 长袁贵仁主持研讨并讲话。会议提出, 要加强组织领导, 并建立健全高校意识形态工作机制, 把核心价值观融入社 会实践、校园文化、学校管理之中, 还强调了要构建高校 宣传思想工作队伍, 加强高校师德建设, 培养德才兼备的 教师队伍等。[1]这是中国高等教育管理部门对高校思想政 治教育, 特别是社会主义核心价值观教育的一种最新的表 态。从这里我们也可以看出, 中国高校管理层对思想政治 教育状况的判断是比较客观的, 提出的措施也比较全面, 但是如何把这些措施落实到教学过程中, 才是改变思想政 治教育状态的关键。

\section{2. 中国高校的思想政治教育: 有关的历史和当前的 核心争议}

自 1949 年 10 月 1 日, 中华人民共和国成立以后, 中 国高校就逐步建立了自己的思想政治教育体系。这个教育 体系, 在内容上是以马克思主义理论教育, 特别是毛泽东 思想教育为中心的。对于一个新成立的国家来说, 这一教 育十分重要。“在确保全体人民对特殊的生活方式和对执政 党的忠诚与热心服务的过程中, 建立了精心设计的说服教 育机构。学校以及经常与之联系的青年组织, 起着核心的 作用。20 世纪, 由于它的各种革命运动和互相竞争的意识 形态, 成了一个确立信念的时代, 其中, 教育资源经常被 巧妙地利用。”[2]毛泽东特别强调, “在知识分子当中提倡 学习马克思主义是很有必要的, 要提倡大家学他十年八年, 马克思主义学得多了, 就会把旧思想推了出去。”[3]让作为 社会精英的高校学生, 首先建立起对党和政府的绝对忠诚, 对社会主义制度的决定忠诚, 成为当时中国高校政治教育 的最重要的目的。但是, 由于中国后来发生了文化大革命, 高等教育基本停办, 思想政治教育也就无从谈起了。

从1978 年底开始, 邓小平启动了中国改革开放的历史 进程。高等学校的政治课再次得到重视。尽管在课程设置 上不断有所调整, 但是, 从核心内容上看, 就是要求教育 学生做到“四个坚持”, 即指坚持社会主义道路, 坚持人民 民主专政, 坚持中国共产党领导, 坚持马克思列宁主义、 毛泽东思想。但是, 随着中国改革开放程度的加剧, 西方 思想在高校传播开来。当 1989 年五六月, 北京出现政治风 波时, 邓小平就指责高校思想政治教育出现失误并导致了 一系列恶果。作为邓小平的后继者, 江泽民吸取这方面的 教训并特别强调: “大量事实证明, 思想文化阵地, 马克思
主义、无产阶级的思想不去占领, 各种非马克思主义、非 无产阶级的思想甚至反马克思主义的思想就会去占领。”[4] 他指出, 思想文化阵地应该宣传科学理论、传播先进文化、 塑造美好心灵, 决不能给那些反动的错误观点, 以及危害 人民特别是青少年身心健康的东西提供传播渠道。因此, 在江泽民和胡锦涛时期, 中国高校的思想政治教育工作得 到了重视, 并有所加强。

目前, 中国高校的思想政治课教育内容主要有: 马克 思主义基本原理概论、毛泽东思想和中国特色社会主义理 论体系概论、思想道德修养与法律基础、中国近现代史纲 要、大学生职业生涯规划与就业等。这些课程的设置, 当 然体现了中国的主流意识形态。因为, “主流意识形态构成 一个社会思想文化的中枢和支柱, 构成一个民族精神信仰 的基础和载体, 起着扩大政治认同、进行政治整合、规范 政治行为、增强政治体系的合法性、促进政治稳定的作 用。”[5]加强社会主义核心价值观教育, 就成为中国党和政 府的必然选择。

在中国高校, 虽然有调查显示, $98 \%$ 的大学生认同“社 会主义核心价值观是兴国之魂”, $81 \%$ 的大学生认为“对自 己的成长成才非常有必要”。[6]但是, 中国有一些媒体和高 校学生也认为, 有的高校老师在课堂上, 借授课之际肆意 攻击国家及当前主流价值观, 逢课必讲“燋燋人家国外”, 而“负面的例子全是中国”。为此, 《辽宁日报》派出采编人 员进行了为期 2 个月的调查, 并发表了一篇长文《老师, 请不要这样讲中国》, 劝说某些老师不要在课堂上“呲必中 国”。[7]这一举动, 引发了中国社会对高校思想政治教育的 普遍关注。

目前, 中国高校思想政治教育的最核心的争论, 就是 对“普世价值”的看法。一部分人认为, 中国必须学习西方 的价值观, 中国特色是以特殊性消解普遍性。另一部分人 则认为, “普世价值” 观念是在干预中国的民主政治建设, 以期颠覆和终结共产党领导的国家权力结构, 在本质上是 当代西方话语霸权及其价值渗透方式的表达。当然, 人们 也注意到，作为社会主义核心价值观的 24 个字中的“民主”、 “自由”、“平等”等, 也是直接来自西方话语体系的。这些 词汇到底如何运用到中国当下语境, 这给高校思想政治教 育带来了新的挑战。

\section{3. 中国高校的思想政治教育: 未来展望}

首先, 任何教育活动都不是在真空中进行的。高校教 师和学生无时无刻不受到社会环境的影响。马克思说过: “历史不外是各个世代的依次交替。每一代都利用以前各代 遗留下来的材料、资金和生产力”。[8]中国还是一个发展中 的大国, 发展是中国的第一要务。邓小平指出: “我们的人 
民生活水平和文化水平还不高, 这也不能靠谈论人的价值 和人道主义来解决。离开了这些具体情况和具体任务而谈 人, 这就不是谈现实的人而是谈抽象的人, 就不是马克思 主义的态度, 就会把青年引入歧途。”[9]中国党和政府, 要 不断发展经济, 提高社会开放程度, 释放更多的宽容和自 信，为高校思想政治教育营造更好的空间和氛围。

其次, 中国的意识形态工作要进一步加强。“意识形 态”, “这个概念的出现是作为在标志现代科学诞生的社会 与政治动荡背景下试图发展启蒙运动理想的一部分。”[10] 不论意识形态的用法是多么多种多样, 它仍然联系着人们 对世界、社会和历史的理性认识, 以及对人类理性自决的 理想。当前国际上的意识形态斗争十分激烈。苏联的部长 会议主席雷日科夫就说过, 西方对苏联的文化渗透, “就是 要在过去俄国的原址上, 建立起一个新的国家, 国名可能 还是这个国名, 但人民的心理已完全改变, 传统的价值观 在百姓心目中将不再占有地位。”[11]从这个角度看, 思想 政治教育, 是与整个国家的意识形态工作联系在一起的, 也是与维护国家的文化安全和意识形态安全联系在一起 的。随着中国党和政府对意识形态工作的重视, 相信中国 高校的思想政治教育在师资配备、课程设置、教材选择、 教育方法等方面, 会有进一步的调整。

第三, 要做好高校教师的工作。因为, “教学是一门唯 有在大量亲身实践、反思与实验中才能掌握的艺术。”[12] 教师的教学内容和教学态度, 无疑决定着中国高校思想政 治教育的质量和效果。即使是从职业道德的角度看, 作为 高校教师, 也有必要站在客观的立场, 站在自己专业的角 度, 将一些政治理论和社会主流价值观传授给学生。有人 认为, 部分高校教师带着对社会和生活的不满情绪进入课 堂, 做一些发泄, 并把这种情绪传递给学生, 这是不理智 的, 也是违背职业操守的。当然, 如何教育好高校思想政 治课教师, 那是另外一个论题。

最后, 中国高校的思想政治教育, 要处理好中国话语 与西方话语体系的关系。从世界范围看, 价值观正处于调 整之中。2013 年 1 月 21 日, 美国总统奥巴马在第二任就 职典礼的讲话中指出: “作为美国公民, 有义务塑造我们时 代的辩题, 不仅是通过我们的选票, 而且要为捍卫悠久的 价值观和持久的理想发声。”而作为世界第二号国家, 中国 则强调, “任何外国不要指望中国做他们的附庸, 不要指望 中国吞下损害我国利益的苦果。”[13]中国要发展, 要树立
自己的国家形象, 就必须加强话语体系建设, 着力打造融 通中外的新概念新范畴新表述, 增强在国际上的话语权。 因此, 如何创造新的话语体系并把它运用到中国高校思想 政治课教学当中, 就成为一个新的任务。而最近在中国高 校普遍开展的社会主义核心价值观教育, 可以看作是一种 类似的尝试和努力。当然, 它的具体效果还有待观察。

\section{参考文献(References)}

[1] Xin Jiao, "Symposium of Presidents by the Ministry of Education”, China Education Daily, October 20, 2014.

[2] W.F. Connel, Twentieth Century World History of Education, Fakun Zhang, Nengda Fang, LeTian Li ed. translated, Beijing: People's Education Press, pp. 12,1990.

[3] Zedong Mao Corpus, vol. 8, Beijing: People's Publishing House, pp. 323, 1999.

[4] Zemin Jiang Corpus, vol. 3, Beijing: People's Publishing House, pp. 97, 2006.

[5] Leisheng Zhang, Marxism and Ideology, vol. 4, Beijing: Higher Education Press, pp.18, 2006.

[6] http://gb.cri.cn/42071/2015/03/11/7211s4898430.htm

[7] “An Open Letter to Ideology Teacher in Colleges", Liaoning Daily, November 13, 2014.

[8] Central Compilation and Translation Bureau, Marx and Engels, Selected Works, vol. 1, Beijing: People's Publishing House, pp. 88,1995 .

[9] Xiaoping Deng Corpus, vol. 3, Beijing: People's Publishing House, pp. 41,1993.

[10] J.B. Tompson, Ideology and Modern Culture, Xian Gao translated, Yilin Press, pp. 35,2005.

[11] W. Hans, Ethics, American Research Methods, Yue Meng translated, Beijing: Social Sciences Academic Press, pp. $56,1994$.

[12] D. Bill, Cultural Contradictions of Capitalism, Yifan Zhao, Long $\mathrm{Pu}$, Xiaojin Ren translated, Joint Publishing, pp. $122,1989$.

[13] Xiaoping Deng Corpus, vol. 3, Beijing: People's Publishing House, pp. 3, 1993. 